\title{
Inhibitory effect of a water-soluble extract from the culture medium of Ganoderma lucidum (Rei-shi) mycelia on the development of pulmonary adenocarcinoma induced by $\mathrm{N}$-nitrosobis (2-hydroxypropyl) amine in Wistar rats
}

\author{
NAOKI KASHIMOTO ${ }^{1,2}$, MINORU HAYAMA ${ }^{2}$, KENJI KAMIYA $^{1}$ and HIROMITSU WATANABE ${ }^{1}$ \\ ${ }^{1}$ Department of Experimental Oncology, Research Institute for Radiation Biology and Medicine, Hiroshima University, \\ Kasumi 1-2-3, Minami-ku, Hiroshima 734-8553; ${ }^{2}$ Health Care Institute Wakunaga Pharmaceutical Co Ltd., \\ 1624 Shimokoutachi, Koda-cho, Akitakata, Hiroshima 739-1195, Japan
}

Received July 15, 2006; Accepted August 28, 2006

\begin{abstract}
A water-soluble extract from the culture medium of Ganoderma lucidum (Rei-shi) mycelia (MAK) has been shown to exert a potent chemopreventive effect. The present study was designed to investigate the effects of dietary MAK supplementation on the development of lung tumors initiated by $\mathrm{N}$-nitrosobis (2-hydroxypropyl) amine (BHP) in male Slc:Wistar rats. A total of 77 animals, 6 weeks of age, were divided into 5 groups and given BHP $(2,000 \mathrm{ppm})$ in their drinking water for 10 weeks. The normal controls were not supplied with BHP. After treatment with the carcinogen, the rats were fed a normal control MF solid diet, or the same diet containing MAK $(1.25 \%, 2.5 \%$ or $5 \%)$ for 12 weeks. Macroscopically, all the doses of MAK reduced the number of nodules, and the effect of 5\% MAK was found to be especially significant. Microscopically, an increase in the number of proliferating cell nuclear antigen (PCNA)-negative tumors and a decrease in the number of tumors strongly positive for PCNA were observed in the tissue sections from the rats that had received all the doses of MAK. The present results thus indicate that dietary supplementation with MAK inhibits the
\end{abstract}

Correspondence to: Dr Hiromitsu Watanabe, Department of Experimental Oncology, Research Institute for Radiation Biology and Medicine, Hiroshima University, Kasumi 1-2-3, Minami-ku, Hiroshima 734-8553, Japan

E-mail: tonko@hiroshima-u.ac.jp

Abbreviations: BHP, N-nitrosobis (2-hydroxypropyl) amine; PCNA, proliferating cell nuclear antigen; PBS, phosphate-buffered saline; BSA, bovine serum albumin; IgG, immunoglobulin $\mathrm{G}$; COX, cyclooxygenase

Key words: lung tumor inhibition, N-nitrosobis (2-hydroxypropyl) amine, Ganoderma lucidum, Wistar rats development of lung tumors, suggesting that MAK may be a potent chemopreventive agent against lung carcinogenesis.

\section{Introduction}

Ganoderma lucidum (Fr.) Karst. (Polyporaceae) is a medicinal mushroom known to the Japanese as Rei-shi or Mannentake, or to the Chinese as 'Lingzhi'. Its fruiting bodies have been used for their medicinal properties in traditional Chinese medicine for over 2000 years. This mushroom is described in detail in the Chinese classics, Shen Nung Ben Cao Jin (dated 206 BC - 8 AD), and the Compendium of Ganoderma lucidum has been used in traditional Chinese medicine for the promotion of vitality and longevity, and within the present decade for the treatment of debility and weakness, hypertension, cardiovascular disease, bronchitis, arthritis, neurasthenia, insomnia, hepatopathy, chronic hepatitis, nephritis, gastric ulcers, asthma, diabetes, altitude sickness, AIDS, and cancer (1-3), in China and other oriental countries. The mycelia of Ganoderma is consumed as health food and herbal medicines. Chemical investigations of the fruiting bodies, spores, and the mycelia of Ganoderma lucidum have shown that they contain various bioactive substances, including polysaccharides, proteins, nucleosides, fatty acids, terpenoids, sterols, and cerebrosides (4). Water or alcohol extracts of Ganoderma lucidum have been used to investigate biological activities, as these extracts contain compounds with immunological and anti-inflammatory properties. Of particular interest among the reported biological/pharmacological properties of Ganoderma lucidum are their anti-tumor activities, including cell cycle arrest, apoptosis induction, motility inhibition, antiangiogenesis, and antimutagenesis (3,5-10).

A water-soluble extract from the culture medium of Ganoderma lucidum (Rei-shi) mycelia (MAK) contains various kinds of high-molecular-weight constituents, such as polysaccharides with protein or water-soluble lignin, and low-molecular-weight constituents, such as triterpenes. We 
have reported previously that MAK prevented the development of azoxymethane-induced aberrant crypt foci and colon tumors in $\mathrm{F} 344$ rats $(11,12)$, and $\mathrm{N}, \mathrm{N}^{\prime}$-dimethyl-hydrazineinduced colon tumors in ICR mice (13).

To determine whether MAK may exert a chemopreventive effect on the carcinogenesis of organs other than the colon, the present study was conducted assessing the effects of MAK on the development of rat lung tumors after initiation with BHP.

\section{Materials and methods}

Animals. Seventy-seven 6-week-old male Slc:Wistar rats (SLC Japan Inc., Hamamatsu, Japan) were used in the present study. They were housed three or four to a polycarbonate cage and kept under constant temperature conditions $\left(24 \pm 2^{\circ} \mathrm{C}\right)$ and relative humidity $(55 \pm 10 \%)$ with a $12 \mathrm{~h}$ light/ dark cycle. The animals were maintained in accordance with the 'Guidelines for the Care and Use of Laboratory Animals' established by Hiroshima University and fed a commercial MF diet (Oriental Yeast. Co. Ltd., Tokyo, Japan) alone or with a $1.25 \%, 2.5 \%$ or $5 \%$ supplement of MAK. Normal tap water was also provided ad libitum.

BHP. The carcinogen was purchased from Nakarai Tesque Co. Inc., Kyoto, Japan, and dissolved in distilled water at a concentration of 2,000 mg/l just before use. This solution was supplied to the rats ad libitum for 10 weeks from lightopaque bottles exchanged at 2- or 3-day intervals.

$M A K$. A water-soluble extract from the culture medium of Ganoderma lucidum mycelia (designated as MAK) was prepared by Noda Shokkin-Kogyo Co., Ltd. (Chiba, Japan). In brief, Ganoderma lucidum (Rei-shi or Mannnentake) mycelia were cultured in a solid medium composed mainly of sugar-cane bagasse for three months, then the whole medium containing the mycelia was extracted with hot water. The extract was filtered and spray-dried to obtain MAK.

Pathology. The animals were sacrificed and necropsied if they became moribund, and all the remaining rats were sacrificed 22 weeks after the BHP treatment. The lungs were removed and the location and size of the individual tumors was recorded. All the tissues were fixed in $10 \%$ neutral formalin. Lesions in the lung were classified into four types: Hyperplasia, adenoma, adenocarcinoma, and squamous cell carcinoma. Data indicate both the total number of tumors and the average diameter of the tumors measured in each section of five lobules.

Immunohistochemistry. Paraffin-embedded sections were deparaffinized in xylene, and rehydrated through a graded ethanol series. A $0.05 \mathrm{M}$ PBS buffer was used to prepare the solutions and also for the washes between the various steps. The incubations were performed in a humidified chamber. Three-micrometer-thick sections were treated for $30 \mathrm{~min}$ at room temperature with $2 \% \mathrm{BSA}$ and incubated with primary antibodies against $B$-catenin (diluted 1:100; Transduction Laboratories, BD 610153, KY, USA), monoclonal mouse anti-proliferating cell nuclear antigen antibody (Dako-PCNA,
PC 10, code No. M 879), monoclonal mouse anti-cyclooxygenase-1 (diluted 1:50; Santa Cruz Biotechnology, sc-1754) and monoclonal mouse anti-cyclooxygenase-2 (diluted 1:100; Santa Cruz Biotechnology, sc-1746) for $1 \mathrm{~h}$ at room temperature. For each case, negative controls were performed on serial sections whereby incubation with the primary antibody was omitted. All the slides were then exposed to the secondary antibody, biotinylated horse anti-universal-monkey IgG (Vectastain Universal Quick Kit, Vector Laboratories, CA, USA, Catalog No PK-8800) and peroxidase-conjugated streptavidin complex. Peroxidase activity was visualized by treatment with $\mathrm{H}_{2} \mathrm{O}_{2}$ and diaminobenzidine for $5 \mathrm{~min}$. At the final step, the sections were counterstained with hematoxylin for $1 \mathrm{~min}$. $\beta$-catenin-positive nuclei were counted and divided by the total epithelial cells in the tumors to give an index for nuclear accumulation. The PCNA index was classified into four types: -, Negative $(0 \%)$; \pm , slightly positive $(<50 \%) ;+$, positive $(<80 \%) ;++$, strongly positive $(>80 \%)$. The PCNA index was calculated from the intensity of PCNA staining of 100 randomly selected tumors in sections of five lobules.

Statistical significance. Statistical significance was determined using Dunnett's method for multiple comparisons, the $\chi^{2}$ and the Student's t-test.

\section{Results}

The intake of drinking water in the BHP treatment groups (6.7 to $7.1 \mathrm{ml} /$ day/animal) was significantly decreased as compared with the normal controls $(18.5 \mathrm{ml} /$ day/animal $)$ but there was no significant difference among the BHP treatment groups. The diet intake also showed no significant difference among the experimental groups after BHP treatment (data not shown).

All of the animals survived until the scheduled time of sacrifice. Body weight in the BHP alone group was significantly decreased as compared with the normal value $(\mathrm{P}<0.01)$ (Table I). In the BHP alone group, thyroid weight was significantly increased relative to the control $(\mathrm{P}<0.01)$, and the weight of the liver, testis and adrenal gland was significantly decreased. The relative weight of the thyroid was significantly increased as compared with the normal control value, whereas that of the lung and testis was significantly decreased (Table I).

Macroscopically, BHP-treated animals had many lung nodules. Both the number of nodules in the animals given $\mathrm{BHP}+5 \% \mathrm{MAK}$ and the mean diameter of nodules in all the MAK groups were significantly decreased in comparison with the corresponding values in the BHP alone group $(\mathrm{P}<0.01)$ (Table II).

Microscopically, as shown in Fig. 1, lesions in the lung were classified into four types: Hyperplasia, adenoma, adenocarcinoma, and squamous cell carcinoma. BHP-treated animals had pulmonary hyperplasia, adenoma and adenocarcinoma, and also thyroid tumors. Squamous cell carcinomas were also evident in $13 \%, 6 \%, 20 \%$ and $0 \%$ of the animals in the BHP, $\mathrm{BHP}+1.25 \% \mathrm{MAK}, \mathrm{BHP}+2.5 \% \mathrm{MAK}$ and the $\mathrm{BHP}+5 \%$ MAK groups, respectively (Table III). The numbers of pulmonary tumors and adenomas in all the MAK groups and adenocarcinomas in the $\mathrm{BHP}+2.5 \% \mathrm{MAK}$ and $\mathrm{BHP}+5 \%$ 
Table I. Body weight and organ weight (relative weight).

\begin{tabular}{|c|c|c|c|c|c|c|c|c|c|}
\hline & $\begin{array}{c}\text { Body } \\
\text { weight (g) }\end{array}$ & Heart (g) & Thyroid (mg) & Lung (g) & Liver (g) & Kidney (g) & Testis (g) & $\begin{array}{c}\text { Adrenal } \\
\text { gland (mg) }\end{array}$ & Spleen (g) \\
\hline Normal & $498.1 \pm 8.9$ & $\begin{array}{c}1.35 \pm 0.03 \\
(0.27 \pm 0.01)\end{array}$ & $\begin{array}{c}40.0 \pm 1.8 \\
(79.9 \pm 3.6)\end{array}$ & $\begin{array}{c}1.59 \pm 0.04 \\
(0.32 \pm 0.01)\end{array}$ & $\begin{array}{l}12.61 \pm 0.28 \\
(2.53 \pm 0.04)\end{array}$ & $\begin{array}{c}2.51 \pm 0.04 \\
(0.51 \pm 0.01)\end{array}$ & $\begin{array}{c}3.17 \pm 0.15 \\
(0.64 \pm 0.03)\end{array}$ & $\begin{array}{c}44.4 \pm 1.5 \\
(89.4 \pm 3.3)\end{array}$ & $\begin{array}{r}0.94 \pm 0.33 \\
(184.3 \pm 62.3)\end{array}$ \\
\hline BHP & $429.4 \pm 16.5^{\mathrm{a}}$ & $\begin{array}{c}1.25 \pm 0.02 \\
(0.30 \pm 0.02)\end{array}$ & $\begin{array}{c}94.9 \pm 9.5^{\mathrm{a}} \\
\left(226.4 \pm 24.2^{\mathrm{a}}\right)\end{array}$ & $\begin{array}{c}1.65 \pm 0.04 \\
\left(0.40 \pm 0.02^{\mathrm{a}}\right)\end{array}$ & $\begin{array}{l}11.04 \pm 0.21^{\mathrm{a}} \\
(2.65 \pm 0.17)\end{array}$ & $\begin{array}{c}2.36 \pm 0.05 \\
(0.56 \pm 0.03)\end{array}$ & $\begin{array}{c}1.14 \pm 0.04^{\mathrm{a}} \\
\left(0.27 \pm 0.02^{\mathrm{a}}\right)\end{array}$ & $\begin{array}{c}35.7 \pm 1.5^{\mathrm{a}} \\
(85.1 \pm 5.0)\end{array}$ & $\begin{array}{l}0.56 \pm 0.01 \\
(133.1 \pm 8)\end{array}$ \\
\hline $\begin{array}{l}\mathrm{BHP}+1.25 \% \\
\mathrm{MAK}\end{array}$ & $448.9 \pm 3.8$ & $\begin{array}{c}1.24 \pm 0.03 \\
(0.28 \pm 0.01)\end{array}$ & $\begin{array}{c}80.6 \pm 8.1 \\
(180.3 \pm 18.6)\end{array}$ & $\begin{array}{c}1.75 \pm 0.04 \\
(0.39 \pm 0.01)\end{array}$ & $\begin{array}{l}11.63 \pm 0.19 \\
(2.59 \pm 0.03)\end{array}$ & $\begin{array}{c}2.48 \pm 0.06 \\
(0.55 \pm 0.02)\end{array}$ & $\begin{array}{c}1.18 \pm 0.06 \\
(0.26 \pm 0.01)\end{array}$ & $\begin{array}{c}37.8 \pm 1.4 \\
(84.1 \pm 2.9)\end{array}$ & $\begin{array}{r}0.57 \pm 0.02 \\
(127.5 \pm 5.6)\end{array}$ \\
\hline $\begin{array}{l}\text { BHP+2.5\% } \\
\text { MAK }\end{array}$ & $460.7 \pm 12.3$ & $\begin{array}{c}1.29 \pm 0.03 \\
(0.28 \pm 0.01)\end{array}$ & $\begin{array}{c}22 \pm 32.3 \\
(262.7 \pm 69.7)\end{array}$ & $\begin{array}{c}2.04 \pm 0.24 \\
(0.47 \pm 0.09)\end{array}$ & $\begin{array}{l}12.04 \pm 0.33 \\
(2.63 \pm 0.07)\end{array}$ & $\begin{array}{c}2.62 \pm 0.13 \\
(0.59 \pm 0.06)\end{array}$ & $\begin{array}{c}1.23 \pm 0.13 \\
(0.27 \pm 0.03)\end{array}$ & $\begin{array}{c}39.8 \pm 2.2 \\
(89.1 \pm 8.9)\end{array}$ & $\begin{array}{c}0.78 \pm 0.14 \\
(181.4 \pm 44.8)\end{array}$ \\
\hline $\begin{array}{l}\text { BHP }+5 \% \\
\text { MAK }\end{array}$ & $456.8 \pm 4.4$ & $\begin{array}{c}1.29 \pm 0.04 \\
(0.28 \pm 0.01)\end{array}$ & $\begin{array}{c}96.9 \pm 7.6 \\
(212.7 \pm 17.2)\end{array}$ & $\begin{array}{c}1.82 \pm 0.05 \\
(0.40 \pm 0.01)\end{array}$ & $\begin{array}{l}12.24 \pm 0.23 \\
(2.68 \pm 0.04)\end{array}$ & $\begin{array}{c}2.59 \pm 0.04 \\
(0.57 \pm 0.01)\end{array}$ & $\begin{array}{c}1.19 \pm 0.04 \\
(0.26 \pm 0.01)\end{array}$ & $\begin{array}{c}36.7 \pm 1.2 \\
(80.4 \pm 2.6)\end{array}$ & $\begin{array}{r}0.63 \pm 0.03 \\
(137.1 \pm 5.3)\end{array}$ \\
\hline
\end{tabular}

Values are mean $\pm \mathrm{SE}$, ${ }^{\text {a }}$ significantly different from the normal value $(\mathrm{P}<0.01)$.

Table II. Number and size of the lung nodules.

\begin{tabular}{llc}
\hline Group & $\begin{array}{c}\text { Number } \\
\text { of nodules }\end{array}$ & $\begin{array}{c}\text { Mean diameter } \\
\text { of nodules }\end{array}$ \\
\hline BHP & $58.7 \pm 6.2$ & $3.83 \pm 0.07$ \\
BHP+1.25\% MAK & $44.4 \pm 4.1$ & $3.33 \pm 0.06^{\mathrm{a}}$ \\
BHP+2.5\% MAK & $48.1 \pm 6$ & $3.15 \pm 0.06^{\mathrm{a}}$ \\
BHP+5\% MAK & $35.4 \pm 4.7^{\mathrm{a}}$ & $3.17 \pm 0.07^{\mathrm{a}}$ \\
\hline
\end{tabular}

Values are mean $\pm \mathrm{SE}$, ${ }^{\text {a }}$ ignificantly different from the BHP value $(\mathrm{P}<0.01)$.

MAK groups were significantly decreased in comparison with the BHP alone group (Table IV). The total size of pulmonary tumors and adenomas in the BHP $+5 \%$ MAK group was also significantly lower than that in the BHP alone group $(\mathrm{P}<0.01)$ (Table $\mathrm{V})$.

As shown in Fig. 2, the PCNA index was classified into four types: -, Negative $(0 \%) ; \pm$, slightly positive $(<50 \%) ;+$, positive $(<80 \%) ;++$, strongly positive $(>80 \%)$. The PCNA indices in the pulmonary tumors are shown in Table VI. The numbers of PCNA-negative tumors in the BHP+2.5\% MAK and $\mathrm{BHP}+5 \%$ MAK groups were significantly increased. In the $\mathrm{BHP}+5 \%$ MAK group, the numbers of both positive tumors and strongly positive tumors were significantly decreased in comparison with the BHP alone group. None of the lung tumors showed any nuclear or cytoplasmic staining for $\beta$-catenin, COX-1 or COX-2.

\section{Discussion}

In the present study, MAK did not affect the incidence of tumors, but significantly reduced the number and size of tumors in a dose-dependent manner. There are two interesting reports of studies carried out using a similar animal model of lung carcinogenesis. One involved long-fermented miso, a natural product, which did not affect the incidence or size of tumors, but significantly reduced the number of tumors (14). The other report describes that a combination of an antibiotic, erythromycin, or an anti-inflammatory drug, ampicillin, with a natural product, sho-saiko-to, decreased the incidence, size and number of tumors (15). However, as in the case of MAK and/or miso, the natural product alone did not affect tumor incidence. Drugs used for cancer chemotherapy are known to cause undesirable side-effects. In contrast however, even though natural products possess a less potent anti-tumor effect than chemical compounds, they are superior in terms of safety. MAK, being a natural product, could be useful when used in combination with a chemical compound to slow the progression of tumor growth. However, further studies on the application of natural products are warranted.

Yun et al reported that a total extract of the whole fruiting body of Ganoderma lucidum inhibited the incidence of pulmonary adenoma induced by benzo(a)pyrene (BP) in newborn mice $(16,17)$. The anticancer activity of polysaccharides isolated from Ganoderma lucidum was originally tested in vivo using sarcoma 180 cells transplanted subcutaneously into mice (18). The anticancer effects of Ganoderma lucidum were attributed to the activity of $\beta$-glucans (19), which have also been isolated from other mushrooms and demonstrate potent immunostimulatory activity (20). Therefore, the stimulation of immune effector cells leads to the subsequent production of cytokines, and contributes to the anticancer activity of Ganoderma lucidum (19).

Similar to the results obtained using the mouse sarcoma 180 cell model, a polysaccharide extract of Ganoderma lucidum has also been shown to inhibit the growth of Lewis lung carcinoma cells in mice $(19,21)$. The sulfate derivatives of D-glucans demonstrate a significantly higher antitumor activity against Ehrlich ascites carcinoma (22). Furthermore, water-soluble extracts from the culture medium of Ganoderma lucidum prevent azoxymethan-induced aberrant crypt foci and colon cancer in rats and the development of N,N'dimethylhydrazine-induced colon tumors in ICR mice (11-13). Finally, a Ganoderma lucidum polysaccharide 

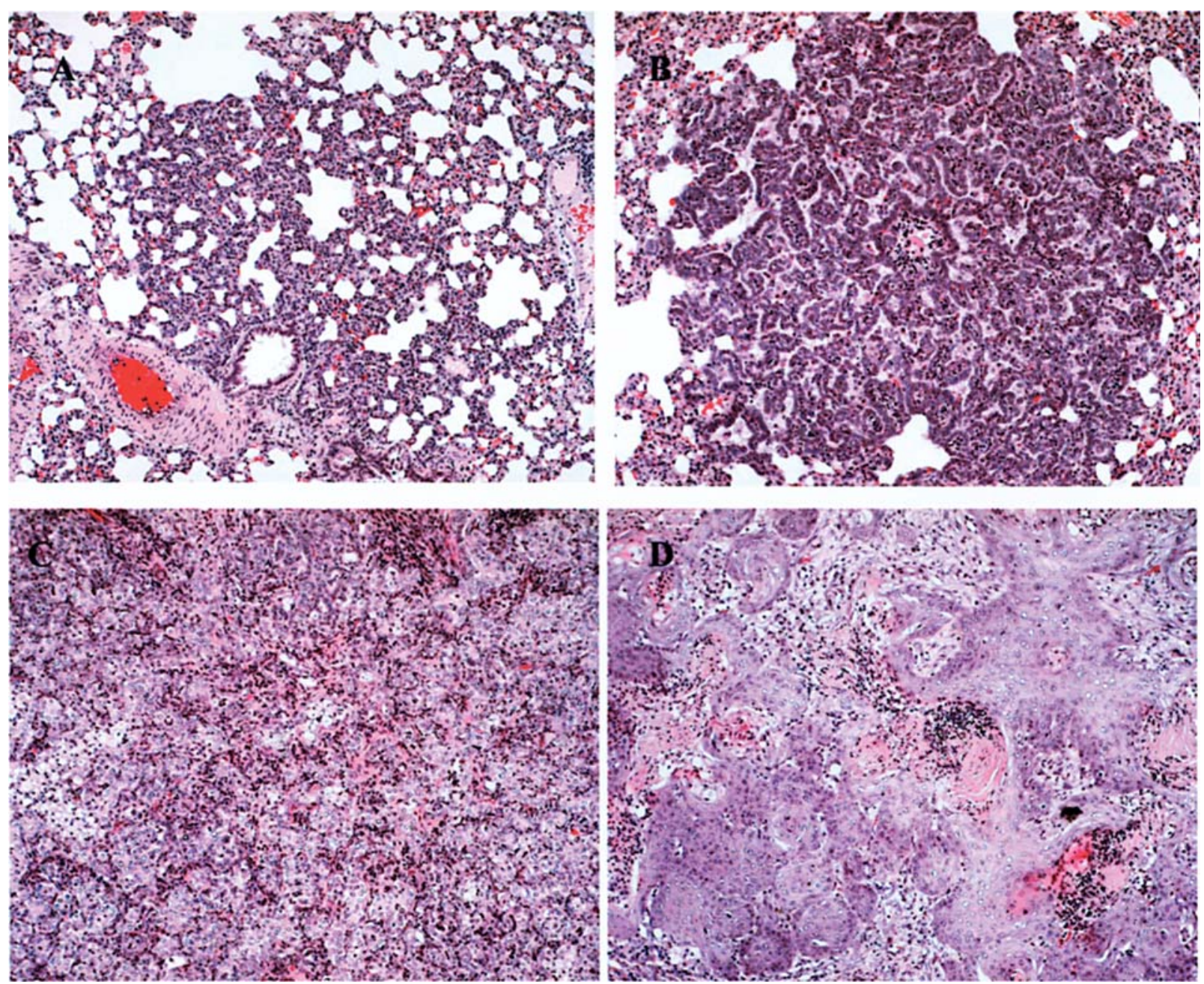

Figure 1. H\&E staining of the lung lesions (x100). (A) Hyperplasia; (B) adenoma; (C) adenocarcinoma; (D) squamous cell carcinoma.

Table III. Tumor incidence.

\begin{tabular}{lcccc}
\hline & $\begin{array}{c}\text { Number of } \\
\text { animals }\end{array}$ & $\begin{array}{c}\text { Pulmonary } \\
\text { tumors }\end{array}$ & $\begin{array}{c}\text { Squamous } \\
\text { cell } \\
\text { carcinoma }\end{array}$ & $\begin{array}{c}\text { Thyroid } \\
\text { tumor }\end{array}$ \\
\hline Normal & 16 & 0 & 0 & 0 \\
BHP & 15 & $15^{\mathrm{a}}(100)^{\mathrm{b}}$ & $2(13)$ & $15(100)$ \\
BHP+1.25\% & 16 & $16(100)$ & $1(6)$ & $16(100)$ \\
MAK & & & & \\
BHP+2.5\% & 15 & $15(100)$ & $3(20)$ & $15(100)$ \\
MAK & & & & $15(100)$ \\
BHP+5\% & 15 & $15(100)$ & 0 & \\
MAK & & & & \\
\hline
\end{tabular}

${ }^{a}$ Number of animals with tumors, bincidence rate

extract (Ganopoly) reportedly stimulates immune function in patients with advanced cancers, including those of the lung, colon, breast, liver, prostate, bladder, and the brain (8). Twelve weeks of treatment with Ganopoly resulted in a significant increase in the plasma concentrations of IL-2, IL- 6 and IFN- $\gamma$
Table IV. Number of pulmonary tumors (per animal). ${ }^{a}$

\begin{tabular}{lccc}
\hline Group & $\begin{array}{c}\text { Total pulmonary } \\
\text { tumors }^{\mathrm{b}}\end{array}$ & Adenoma & Carcinoma \\
\hline BHP & $42.71 \pm 3.07$ & $28.43 \pm 2.86$ & $14.29 \pm 1.27$ \\
BHP+1.25\% & $28.80 \pm 2.14^{\mathrm{c}}$ & $20.27 \pm 1.38^{\mathrm{c}}$ & $11.33 \pm 1.31$ \\
MAK & & & \\
BHP+2.5\% & $24.80 \pm 1.72^{\mathrm{c}}$ & $23 \pm 1.90^{\mathrm{c}}$ & $9.20 \pm 1.20^{\mathrm{c}}$ \\
MAK & & & \\
BHP+5\% & $24.50 \pm 2.42^{\mathrm{c}}$ & $19.20 \pm 2.50^{\mathrm{c}}$ & $8.29 \pm 1.18^{\mathrm{c}}$ \\
MAK & & & \\
\hline
\end{tabular}

aData indicate the total number of tumors measured in each section of 5 lobules; ${ }^{b}$ adenoma + adenocarcinoma; values are mean $\pm \mathrm{SE}$; ${ }^{\mathrm{c}}$ significantly different from the BHP value $(\mathrm{P}<0.01)$.

and enhanced NK activity, whereas the levels of IL-1 and TNF- $\alpha$ were significantly decreased (8).

In the present study, by classifying the PCNA index into four types - negative, slightly positive, positive or strongly positive - by microscopic observation of 100 random tumors from five lobules of the lung, MAK was found to decrease 
Table V. Size of the pulmonary tumors $(\mathrm{mm}){ }^{\mathrm{a}}$

\begin{tabular}{lccc}
\hline Group & $\begin{array}{c}\text { Total pulmonary } \\
\text { tumor }\end{array}$ & Adenoma & Carcinoma \\
\hline BHP & $1.07 \pm 0.03$ & $0.99 \pm 0.03$ & $1.23 \pm 0.06$ \\
BHP+1.25\% & $1.11 \pm 0.04$ & $0.93 \pm 0.03$ & $1.37 \pm 0.08$ \\
MAK & & & \\
BHP+2.5\% & $1.06 \pm 0.04$ & $0.93 \pm 0.03$ & $1.31 \pm 0.07$ \\
MAK & & & \\
BHP+5.0\% & $0.93 \pm 0.03^{\mathrm{b}}$ & $0.85 \pm 0.03^{\mathrm{b}}$ & $1.14 \pm 0.07$ \\
MAK & & & \\
\hline
\end{tabular}

aData indicate the average diameter of the tumors measured in each section of five lobules; values are mean $\pm \mathrm{SE}$; ${ }^{\mathrm{b}}$ significantly different from the BHP value $(\mathrm{P}<0.01)$

the number of strongly positive tumors and increase the number of negative tumors in a dose-dependent manner. In the present study, MAK attenuated the up-regulated cell cycle activity during carcinogenesis after exposure to the carcinogen. As a similar effect has also been reported in an animal model of colon carcinogenesis (11-13), MAK is thought to function in this way to achieve its anti-tumor effect. MAK did not influence the cell cycle of normal tissue close to carcinoma lesions (data not shown), and this has also been reported in the colon carcinogenesis animal model. Accordingly, MAK is thought to have no effect on the proliferation of normal epithelial cells. In addition, macroscopic observation revealed that MAK reduced the number and size of tumors induced by the carcinogen, and this reflected the decrease in the number of PCNA-positive carcinomas. A recent study has shown that for the prevention of tumor formation it is important to arrest the apoptosis guidance ability of p53 and the destabilization of the genome, and the destabilized prevention of a genome may be attained by the guidance of a cell cycle stop (23). Therefore, it is shown that MAK counteracts the up-regulation of the cell cycle in association with proteins such as p53, or contributes to gene stability. Further study is needed to shed more light on the function of MAK.

In addition to in vivo biological activities other than anticancer effects, the intragastric application of poly-
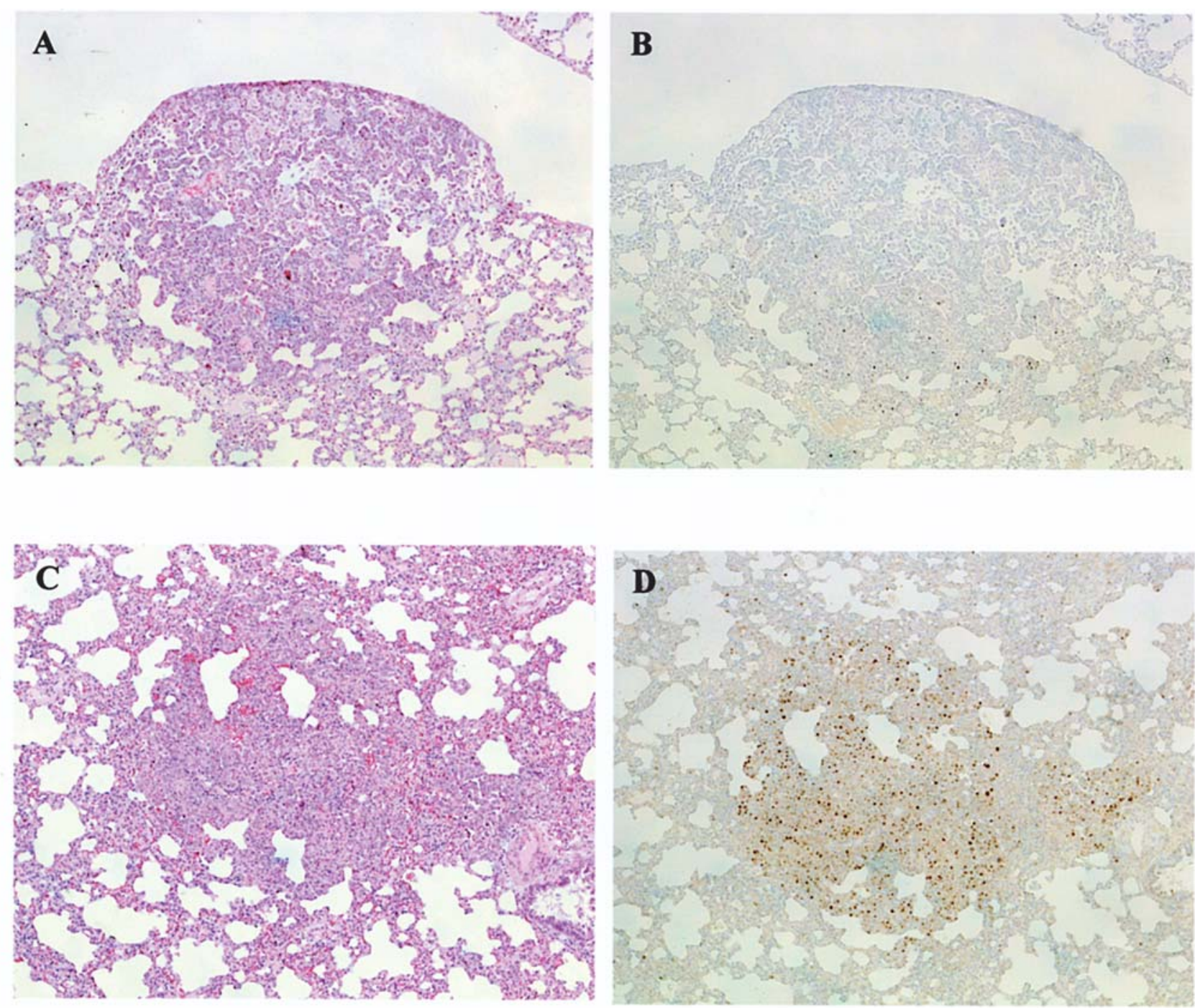

Figure 2. H\&E and PCNA staining of the lung lesions (x100). (A) H\&E staining on the 5\% MAK+BHP group rats; (B) PCNA staining on (A) as classified to negative; (C) H\&E staining on the BHP group rats; (D) PCNA staining on (C) as classified to strong positive. 
Table VI. Immunochemistry study (PCNA) ${ }^{\text {a }}$

\begin{tabular}{lcccc}
\hline Group & - & \pm & + & ++ \\
\hline BHP & $4.85 \pm 6.50$ & $45.38 \pm 17.69$ & $41.28 \pm 15.99$ & $8.48 \pm 9.97$ \\
BHP+1.25\% & $6.55 \pm 5.84$ & $54.29 \pm 22.02$ & $34.12 \pm 21.63$ & $5.03 \pm 7.10$ \\
MAK & & & $28.36 \pm 12.69$ & $2.56 \pm 3.57^{\mathrm{b}}$ \\
BHP+2.5\% & $13.81 \pm 10.02^{\mathrm{b}}$ & $55.26 \pm 6.95$ & $17.85 \pm 19.46^{\mathrm{b}}$ & $0.93 \pm 1.84^{\mathrm{b}}$ \\
MAK & & & & \\
BHP+5.0\% & $25.08 \pm 12.91^{\mathrm{b}}$ & $56.14 \pm 15.12$ & & \\
MAK & & & & \\
\hline
\end{tabular}

aThe PCNA index was calculated from the intensity of the PCNA staining of 100 randomly selected tumors in sections of five lobules; values are mean \pm S.E.; ${ }^{\mathrm{b}}$ significantly different from the BHP value $(\mathrm{P}<0.05$ and 0.01$) ;-$, negative; \pm , slightly positive; + , positive; ++ , strongly positive.

saccharide has been shown to prevent indomethacin- and acetic acid-induced gastric mucosal lesions in rats (24). The hepatoprotective effects of the Ganoderma lucidum polysaccharide have also been evaluated in a mouse infection model utilizing Bacillus Calmette-Guerin (25). Treatment with the polysaccharide diminished the histological changes associated with liver injury, such as hemorrhage and necrosis in the hepatic lobules and the inflammatory infiltration of lymphocytes and Kupffer cells around the central vein (25). Glycans known as ganoderan A and B isolated from the fruiting bodies of Ganoderma lucidum have been shown to possess hypoglycemic activity (26). Both ganoderans reduced the plasma glucose levels in normal mice and mice with alloxan-induced hyperglycemia (26). Ganoderan B increased the level of insulin in the plasma but did not have any effect on insulin binding to isolated adipocytes (27). Ganoderan B also reduced the glycogen content of the liver but had no influence on total cholesterol and triglyceride levels in the plasma and liver (27). Polysaccharides isolated from the fruiting body demonstrate protective effects against alloxaninduced damage to insulin-producing pancreatic $\beta$ cells, increasing their viability and protecting them from necrosis (28). A water extract of mycelia has also been assessed for cardiovascular activity in rabbits and rats, and was found to decrease systolic and diastolic blood pressure (29). Cao and Lin observed that Ganoderma lucidum polysaccharides and peptide inhibited in vivo angiogenesis using the chick chorioallantoic membrane assay $(9,30)$.

In an in vivo experiment, oral administration of the triterpenoid fraction of the fruiting body of Ganoderma lucidum inhibited the growth of intrasplenic implants of Lewis lung carcinoma in mice (31). In addition, the triterpenoid fraction prevented the invasion of metastatic tumor cells into the white pulp of the spleen and hepatic parenchyma (31). Furthermore, matrigel-induced neovascularization was also inhibited, and the biologically active compound responsible for the suppression of angiogenesis was identified as ganodric acid F (31). Combined treatment with lovastatin and an oxygenated triterpenoid fraction from Ganoderma lucidum inhibited the growth of human hepatoma Hep 3B cells (3). Moreover, lovastatin and the triterpenoid fraction reduced the growth of tumors in nude mice with orthotopically inoculated human hepatoma Hep 3B/T2 cells (25). These data suggest that triterpenoids from Ganoderma lucidum may have potential as an adjuvant therapy for the treatment of cancer. All of the above studies clearly show that Ganoderma lucidum possesses antitumor and immunomodulatory potential.

In conclusion, the results of the present study indicate that Ganoderma lucidum may be a useful chemopreventive agent, and that further study is warranted to identify the active component involved in its effect. Studies are now in progress in our laboratory to further clarify the active compounds in the water-soluble extract and investigate their pharmaceutical effects.

\section{References}

1. Lin ZB: Pharmacological functions of Ganoderma lucidum In: Modern Research of Ganoderma lucidum. Z.B. Lin (ed). 2nd edition. Beijing Medical University Press, pp284-309, 2001.

2. Wasser SP and Weis AL: Medicinal properties of substances occurring in higher basidiomycetes mushrooms: current perspective. Int J Med Mushrooms 1: 31-62, 1999.

3. Shiao MS: Natural products of the medicinal fungus Ganoderma lucidum: occurrence, biological activities, and pharmacological functions. Chem Rec 3: 172-180, 2003.

4. Yeung WH, Lu QY, Zhang Q and Go VLW: Chemical and biochemical basis of the potential anti-tumor properties of Ganoderma lucidum. Curr Top Nutraceutical Res 2: 67-77, 2004.

5. Hu H, Ahn NS, Yang X, Lee YS and Kang KS: Ganoderma lucidum extract induces cell cycle arrest and apoptosis in MCF-7 human breast cancer cell. Int J Cancer 102: 250-253, 2002.

6. Sliva D, Labarrere C, Slivova V, Sedlak M, Lloyd FP Jr and Ho NW: Ganoderma lucidum suppresses motility of highly invasive breast and prostate cancer cells. Biochem Biophys Res Commun 298: 603-612, 2002.

7. Ghafar MA, Golliday E, Bingham J, Mansukhani MM, Anastasiadis AG and Katz AE: Regression of prostate cancer following administration of genistein combined polysaccharide $\left(\mathrm{GCP}^{\mathrm{TM}}\right)$, a nutritional supplement: a case report. J Altern Complement Med 8: 493-497, 2002.

8. Gao Y, Zhou S, Jiang W, Huang M and Dai X: Effects of ganopoly (a Ganoderma lucidum polysaccharide extract) on the immune functions in advanced-stage cancer patients. Immunol Invest 32: 201-215, 2003.

9. Song YS, Kim SH, Sa JH, Jin C, Lim CJ and Park EH: Antiangiogenic and inhibitory activity on inducible nitric oxide production of the mushroom Ganoderma lucidum. J Ethnopharmacol 90: 17-20, 2004

10. Lakshmi B, Ajith TA, Sheena N, Gunapalan N and Janardhanan KK: Antiperoxidative, anti-inflammatory, and antimutagenic activities of ethanol extract of the mycelium of Ganoderma lucidum occurring in South India. Teratog Carcinog Mutagen 1 (suppl): 85-97, 2003. 
11. Lu H, Uesaka T, Katoh O, Kyo E and Watanabe H: Prevention of the development of preneoplastic lesions, aberrant crypt foci, by a water-soluble extract from cultured medium of Ganoderma lucidum (Rei-shi) mycelia in male F344 rats. Oncol Rep 8: 1341-1345, 2001.

12. Lu H, Kyo E, Uesaka T, Katoh $\mathrm{O}$ and Watanabe H: A watersoluble extract from cultured medium of Ganoderma lucidum (Rei-shi) mycelia suppresses azoxymethane-induction of colon cancers in male F344 rats. Oncol Rep 10: 375-379, 2003.

13. Lu H, Kyo E, Uesaka T, Katoh O and Watanabe H: Prevention of development of N,N'-dimethylhydrazine-induced colon tumors by a water-soluble extract from cultured medium of Ganoderma lucidum (Rei-shi) mycelia in male ICR mice. Int J Mol Med 9: 113-117, 2002.

14. Shiraki K, Une K, Yano R, Otani S, Mimeoka A and Watanabe H: Inhibition by long-term fermented miso of induction of pulmonary adenocarcinoma by diisopropanolnitrosamine in Wistar rats. Hiroshima J Med Sci 52: 9-13, 2003.

15. Tsutsumi M, Kitada H, Shiraiwa K, Takahama M, Tsujiuchi T, Sakitani H, Sasaki Y, Murakawa K, Yoshimoto M and Konishi Y: Inhibitory effects of combined administration of antibiotics and anti-inflammatory drugs on lung tumor development initiated by $\mathrm{N}$-nitrosobis (2-hydroxypropyl) amine in rats. Carcinogenesis 21: 251-256, 2000

16. Yun TK, Kim SH and Lee YS: Trial of a new medium-term model using benzo(a)pyrene induced lung tumor in newborn mice. Anticancer Res 15: 839-845, 1995.

17. Yun TK: Update from Asia. Asian studies on cancer chemoprevention. Ann NY Acad Sci 889: 157-192, 1999.

18. Miyazaki T and Nishijima M: Studies on fungal polysaccharides. XXVII. Structural examination of a water-soluble, antitumor polysaccharide of Ganoderma lucidum. Chem Pharm Bull (Tokyo) 29: 3611-3616, 1981.

19. Sone Y, Okuda R, Wada N, Kishida E and Misaki A: Structures and anti-tumor activity of Sarcoma aspratus (Berk) S Ito and Ganoderuma lusidum (Fr) Karst. Agric Biol Chem 4: 2441-2653, 1985.

20. Wasser SP: Medicinal mushrooms as a source of antitumor and immunomodulating polysaccharides. Appl Microbiol Biotechnol 60: $258-274,2002$.
21. Furusawa E, Chou SC, Furusawa S, Hirazumi A and Dang Y: Antitumor activities of Ganoderuma lusidum and edible mushroom, on intraperitoneally implanted Lewis lung carcinoma in synergencic mice. Phytother Res 6: 300-304, 1992.

22. Zhang L, Zhang M, Zhou Q, Chen J and Zeng F: Solution properties of antitumor sulfated derivative of alpha-(1->3)-Dglucan from Ganoderma lucidum. Biosci Biotechnol Biochem 64: 2172-2178, 2000

23. Liu G, Parant JM, Lang G, Chau P, Chavez-Reyes A, El-Naggar AK, Multani A, Sandy Chang S and Lozano G: Chromosome stability, in the absence of apoptosis, is critical for suppression of tumorigenesis in Trp53 mutant mice. Nat Genet 36: 63-68, 2004

24. Gao Y, Zhou S, Wen J, Huang M and Xu A: Mechanism of the antiulcerogenic effect of Ganoderma lucidum polysaccharides on indomethacin-induced lesions in the rat. Life Sci 72: 731-745, 2002.

25. Zhang GL, Wang $\mathrm{YH}, \mathrm{Ni} \mathrm{W}$, Teng $\mathrm{HL}$ and Lin ZB Hepatoprotective role of Ganoderma lucidum polysaccharide against BCG-induced immune liver injury in mice. World J Gastroenterol 8: 728-733, 2002.

26. Hikino H, Konno C, Mirin $\mathrm{Y}$ and Hayashi T: Isolation and hypoglycemic activity of ganoderans A and B, glycans of Ganoderma lucidum fruit bodies. Planta Med 55: 339-340, 1985.

27. Hikino H, Ishiyama M, Suzuki Y and Konno C: Mechanisms of hypoglycemic activity of ganoderan B: a glycan of Ganoderma lucidum fruit bodies. Planta Med 55: 423-428, 1989.

28. Zhang HN, He JH, Yuan L and Lin ZB: In vitro and in vivo protective effect of Ganoderma lucidum polysaccharides on alloxan-induced pancreatic islets damage. Life Sci 73: 2307-2319, 2003.

29. Lee SY and Rhee HM: Cardiovascular effects of mycelium extract of Ganoderma lucidum: inhibition of sympathetic outflow as a mechanism of its hypotensive action. Chem Pharm Bull (Tokyo) 38: 1359-1364, 1990.

30. Cao QZ and Lin ZB: Antitumor and anti-angiogenic activity of Ganoderma lucidum polysaccharides peptide. Acta Pharmacol Sin 25: 833-838, 2004.

31. Kimura Y, Taniguchi $M$ and Baba K: Antitumor and antimetastatic effects on liver of triterpenoid fractions of Ganoderma lucidum: mechanism of action and isolation of an active substance. Anticancer Res 22: 3309-3318, 2002. 